\title{
Electric-field profiles in electron-beam-charged polymer electrets
}

\author{
R Gerhard-Multhaupt $\uparrow, M$ Haardt, W Eisenmenger and G M Sessler $\uparrow$ \\ Physikalisches Institut der Universität Stuttgart, Pfaffenwaldring 57, D-7000 Stuttgart 80, \\ Federal Republic of Germany
}

Received 9 March 1983, in final form 23 May 1983

\begin{abstract}
A recently developed method, which uses piezoelectrically generated pressure steps for the determination of electric-field profiles in dielectrics, has been applied to electron-beam-charged polyfluoroethylenepropylene (FEP) and polyethyleneterephthalate (PETP) electrets. The results indicate that the technique can be employed to study volumecharge effects in thin dielectrics. If properly calibrated, the method provides a quantitative measure of charge-integral functions or electric-field distributions in polymer foils.
\end{abstract}

\section{Introduction}

Polymer electrets (Sessler 1980) are gaining more and more practical importance. However, the basic understanding of charge storage and transport in electrets is still limited. For example, the spatial charge or field distributions in thin charge-retaining polymer foils could not be accurately measured until recently.

Previously suggested techniques for charge or field distribution measurements are based on the diffusion of thermal pulses (Collins 1975, 1976, 1977, 1980, 1981, DeReggi et al 1978, von Seggern 1978), on the diffusion of vapour (Falck et al 1982a, b), on the partial penetration of electron beams (Sessler et al 1977, Tong 1980a, b), and on the propagation of pressure waves (Collins 1977, Laurenceau et al 1976, 1977, Darmon et al 1979, Migliori 1979, Migliori and Thompson 1980) into the sample under investigation. A focus of attention was the use of lasers for the generation of pressure pulses (Rozno and Gromov 1979, 1980, 1981, Alquié et al 1981, 1982, Sessler et al 1981, Migliori and Hofler 1982). Most of these attempts achieved only a limited experimental resolution and thus required a numerical deconvolution procedure.

Direct high-resolution probing of the distribution of real and polarisation charges in thin dielectrics is now possible by means of the destructive electron-beam method (Sessler et al 1982b, Tong 1982) or the non-destructive laser-induced pressure-pulse (LIPP) technique (Sessler et al 1981, 1982a, c), whereas spatial field and polarisation profiles can be directly scanned with piezoelectrically generated pressure steps (PPS) (Eisenmenger and Haardt 1982, Haardt and Eisenmenger 1982). The latter technique, which is based on the propagation of a quartz-generated acoustic step wave through the

\footnotetext{
† Permanent address: Institut für Elektroakustik, Technische Universität Darmstadt, Merckstrasse 25, D-6100 Darmstadt, Federal Republic of Germany.
} 
sample under investigation, has been mostly used for the study of the piezoelectric polymer polyvinylidenefluoride (PVDF) (Eisenmenger and Haardt 1982, Eisenmenger 1982, Eisenmenger et al 1982).

In the present paper, initial results of electric-field distribution measurements on real-charge electrets with the PPS method are reported. The samples used are 23-25 um thick foils of polyfluoroethylenepropylene (FEP) and polyethyleneterephthalate (PETP) charged by means of a monoenergetic electron beam.

\section{Experimental method}

The experimental set-up is schematically depicted in figure 1. A $100 \mathrm{~ns}$ long square pulse with an amplitude of 400 to $600 \mathrm{~V}$ is generated by the relay-triggered discharge of a coaxial cable. The sequence of a positive and a negative voltage step is used to drive a piezoelectric quartz plate of $3 \mathrm{~mm}$ thickness and $25 \mathrm{~mm}$ diameter. A 100 to $200 \mathrm{~nm}$ thick silicone oil layer is used to couple the resulting pressure steps into the sample (Haardt and Eisenmenger 1982). The other surface of the unmetallised sample is contacted by a conducting rubber disc of 4.5 to $5 \mathrm{~mm}$ diameter. Good acoustic contact between quartz plate and sample is maintained by pressing the quartz-oil-sample-rubber sandwich slightly together.

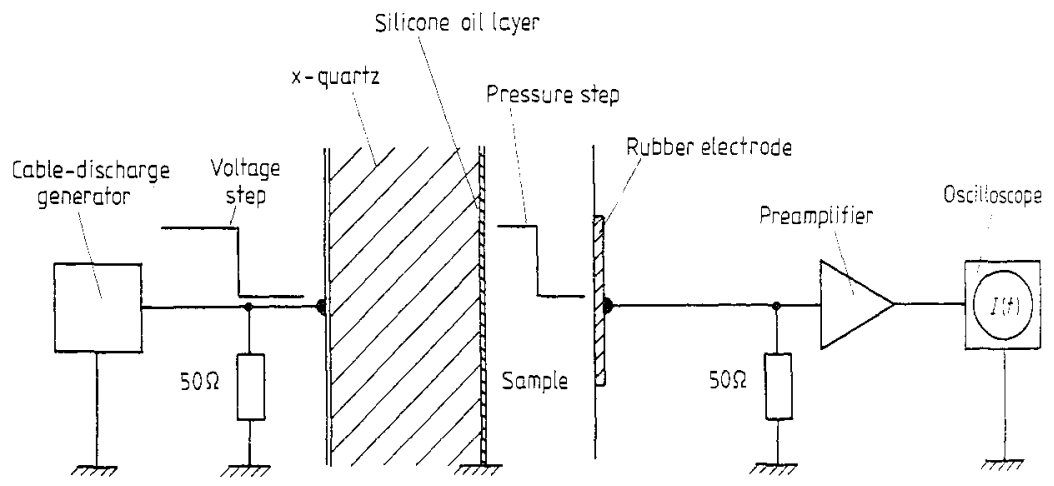

Figure 1. Schematic set-up of the PPS technique.

The rubber electrode diameter of 4.5 to $5 \mathrm{~mm}$ implies sample capacitances of 12 to $15 \mathrm{pF}$ for the $25 \mu \mathrm{m}$ thick Teflon FEP foils $(\varepsilon=2.1)$ and of 20 to $24.5 \mathrm{pF}$ for the $23 . \mathrm{m}$ thick PETP foils $(\varepsilon=3.25)$. Thus, the resulting $R C$ time constants $(R=50 \Omega)$ of 0.6 to $1.2 \mathrm{~ns}$ affect the temporal resolution of the experiments and the assumed short-circuit conditions. This problem may be overcome by reducing the electrode area and by inserting a second uncharged foil of the same material between sample and rear electrode (Haardt 1982). However, both measures would also reduce the signal amplitude and enlarge the relative influence of edge effects.

The response of a sample is detected between the rubber electrode and the grounded quartz metallisation facing the sample. This signal is fed into a very fast two-stage preamplifier (B \& H models AC 2511 and AC 3011 with 1.7 and $3.15 \mathrm{GHz}$ bandwidths. respectively) the output of which is connected to either a real-time oscilloscope (Tek- 
tronix 7104 with $1 \mathrm{GHz}$ bandwidth) or a sampling oscilloscope (Phillips PM 3400 with 1.7 GHz bandwidth). Permanent records of the sample signal are obtained either by photographing the real-time oscilloscope display or by recording the output signal of the sampling scope. The use of the sampling oscilloscope allows for a significant improvement of the signal-to-noise ratio.

The propagation of a step wave through a sample leads to a compression of the sample volume behind the front of the step wave, which travels with the velocity of sound $c$. In a charged and short-circuited sample, there are electric fields between the charge layers and the accompanying induction charges on the electrodes. The voltage across the specimen, however, must be zero. Thus, the inhomogeneous compression of the sample generated by the propagating pressure step necessitates a temporary rearrangement of the induction charges which manifests itself as a current between the sample electrodes.

A detailed analysis (Gerhard-Multhaupt 1983) leads to the following approximate relation between the short-circuit current $I(t)$ at the time $t$ and the electric field $E(x)$ at the location $x=c t$ of the pressure step in the sample:

$$
I(t)=\frac{\varepsilon_{0} \varepsilon A}{s}\left(\frac{4}{3}+\frac{\varepsilon}{3}-\frac{2}{3 \varepsilon}\right) \frac{p}{\rho_{0} c} E(c t) .
$$

Here $\varepsilon, \rho_{0}, s$ and $A$ are the relative permittivity, the density, the thickness, and the electroded area of the electret sample, respectively, $\varepsilon_{0}$ is the vacuum dielectric constant, $c$ the velocity of longitudinal sound waves in the sample, and $p$ the amplitude of the pressure step.

An alternative approach (Eisenmenger and Haardt 1982, Haardt 1982) using the electrostriction coefficient

$$
\gamma=-(1 / \varepsilon)(\partial \varepsilon / \partial S)
$$

of the sample material ( $S$ is the mechanical strain), expresses the current response $I(t)$ as a function of the integral over the charge distribution $\rho(\xi)$ in the compressed sample volume:

$$
I(t)=\frac{A}{S}(1+\gamma) v \int_{0}^{x=c t} \rho(\xi) \mathrm{d} \xi
$$

where $v$ denotes the particle velocity in the step wave.

Equation (1) can be transformed into equation (2) and vice versa by use of Poisson's equation, the Clausius-Mossotti equation for approximately calculating the electrostriction coefficient $\gamma$, and the relation $v=p /\left(\rho_{0} c\right)$ between particle velocity $v$ and pressure amplitude $p$ of the step wave. If all parameters which do not change during a pressure-step experiment are combined to form a single constant $C$, equations (1) and (2) may be written as follows:

$$
I(t)=C \cdot E(c t)=\frac{C}{\varepsilon_{0} \varepsilon} \int_{0}^{x=c t} \rho(\xi) \mathrm{d} \xi .
$$

The method has been checked and calibrated by means of a layered sample consisting of two $12.5 \mu \mathrm{m}$ thick Teflon-FEP foils with a $100 \mathrm{~nm}$ thick aluminium metallisation and a 100 to $200 \mathrm{~nm}$ thick silicone oil coupling layer between them (Haardt and Eisenmenger 1982, Holdik 1983). When a voltage is applied to its centre electrode this sample behaves like a $25 \mu \mathrm{m}$ thick film with a charge layer in its centre. The pressure-step response of the test sample is depicted in figure 2 (Eisenmenger 1982) where the $x$ axis is adjusted such 


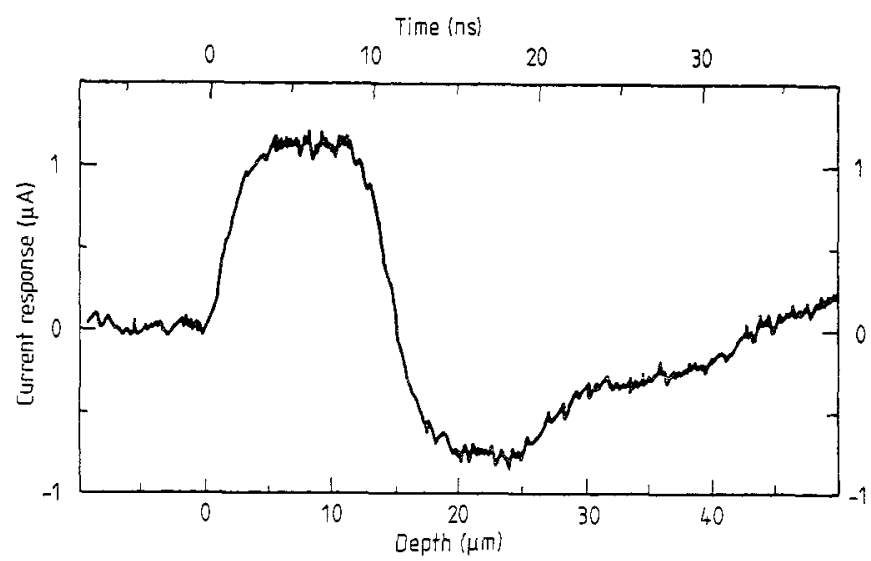

Figure 2. Current response of ( $\cong$ field distribution in) layered test sample (two uncharged 12.5 um Teflon-FEP foils, centre electrode biased).

that its origin coincides with the initial rise of the signal. The calibration of the $x$ axis is obtained from the known sound velocity of $1.3 \mathrm{~km} \mathrm{~s}^{-1}$ (Sessler et al 1982c).

As expected, figure 2 reveals a charge depth (onset of the signal decrease) equal to the thickness of a single foil. The signal shows approximately the expected squarewave-like shape, thus demonstrating the feasibility of the present technique. Deviations from the expected shape are caused by the finite rise time of the pressure step, by the $R C$ time constant of about $0.6 \mathrm{~ns}$, by the mechanical properties of the rubber electrode, and probably by thickness non-uniformities and ultrasonic absorption and dispersion in the polymer foil.

The current signal of the layered sample in figure 2 can be used to determine the calibration factor $C$ in equation (3), since the voltage $V$ applied to the centre electrode generates an electric field $E=V / s_{0}$ in the sample ( $s_{0}$ is the thickness of a single foil). The calibration factor was measured for several centre-electrode voltages and found to be constant (Holdik 1983). Measurements with a voltage step of $400 \mathrm{~V}$ and an electrode area of $22 \mathrm{~mm}^{2}$ resulted in calibration factors $C=3.4 \times 10^{-14} \mathrm{~A} \mathrm{~m} \mathrm{~V}^{-1}$ and $C=3.3 \times 10^{-14} \mathrm{~A} \mathrm{~m} \mathrm{~V}^{-1}$ for a $25 \mu \mathrm{m}$ thick Teflon-FEP sandwich and a $46 \mu \mathrm{m}$ thick Hostaphan-PETP sandwich, respectively. As evident from equations (1)-(3), the calibration factor $C$ depends on several parameters of the actual experiment. Therefore, $C$ has to be adjusted for each measurement (see below).

The pressure amplitude of the step wave in the sample can be calculated from the experimental calibration factors by use of equation (1) or (2). Such calculations yield pressure amplitudes of the order of $10 \mathrm{kPa}$. Pressures of this magnitude are much too small to induce any shock-polarisation effects in the samples, since the threshold pressures for shock-induced polarisation are of the order of $1 \mathrm{GPa}$ (Hauver 1965, Wilhelm 1982).

\section{Results}

All electret samples were electron-beam charged in order to produce a real-charge distribution, the centroid of which is known from other measurements (Gross et al 1977). 


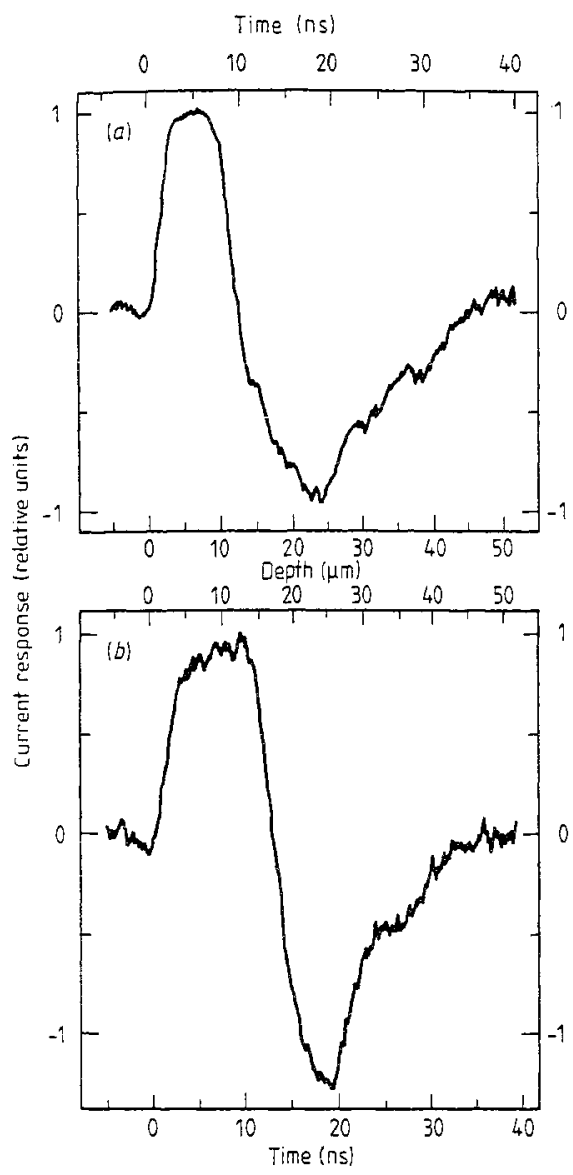

Figure 3. Current response of $(\cong$ field distribution in) $25 \mu \mathrm{m}$ Teflon-FEP charged with a $30 \mathrm{keV}$ electron beam. (a) Step wave entering through charged surface; $(b)$ step wave entering through opposite surface.

Figure 3 shows the pressure-step response of a $25 \mu \mathrm{m}$ thick Teflon-FEP sample which had been metallised on both surfaces, charged for $32 \mathrm{~s}$ with an electron beam of $30 \mathrm{keV}$ energy and $10 \mu \mathrm{A} \mathrm{m}^{-2}$ current density, annealed for about 3 min at $150^{\circ} \mathrm{C}$, and subsequently stored for $3 \mathrm{~d}$. The metal electrodes were removed prior to the measurement. The sample was measured once with the step wave entering at the same surface through which the electron-beam charging had been performed (figure $3(a)$ ) and once with the pressure step entering at the opposite surface (figure $3(b)$ ). The current response is given in relative units only.

In both cases, the signal initially rises quickly to a relatively constant level when the pressure step passes through the sample surface and travels across the electric field between the induction charge on the grounded quartz electrode and the electronbeam-deposited charge layer in the sample. Once the pressure step arrives at this charge layer, the signal changes until the step wave reaches the electric-field zone between the charge layer and the rubber electrode. Finally, the signal returns to zero when the step wave leaves the sample.

Comparison of the two signals in figures $3(a)$ and $3(b)$ reveals that their first parts exhibit the expected more or less rectangular shape while the later parts are somewhat distorted. Especially at the end of the pulse transit, the field-related current response 
does not become zero immediately, but instead decreases more gradually. This phenomenon points to similar effects as in the case of the test sample (figure 2).

The transit time of the step wave through the $25 \mu \mathrm{m}$ thick Teflon-FEP-electret foil amounts to about $19 \mathrm{~ns}$, corresponding to the above-mentioned sound velocity of approximately $1.3 \mathrm{~km} \mathrm{~s}^{-1}$. Electrode and charge-layer positions are deduced from the respective onsets of the steeper parts of the signal. The slopes of the signal are affected by the $R C$ time constant of $0.62 \mathrm{~ns}$. The distance of the charge layer from the front surface follows as about $11 \mu \mathrm{m}$, which agrees well with split-Faraday-cup measurements on the same material (Gross et al 1977).

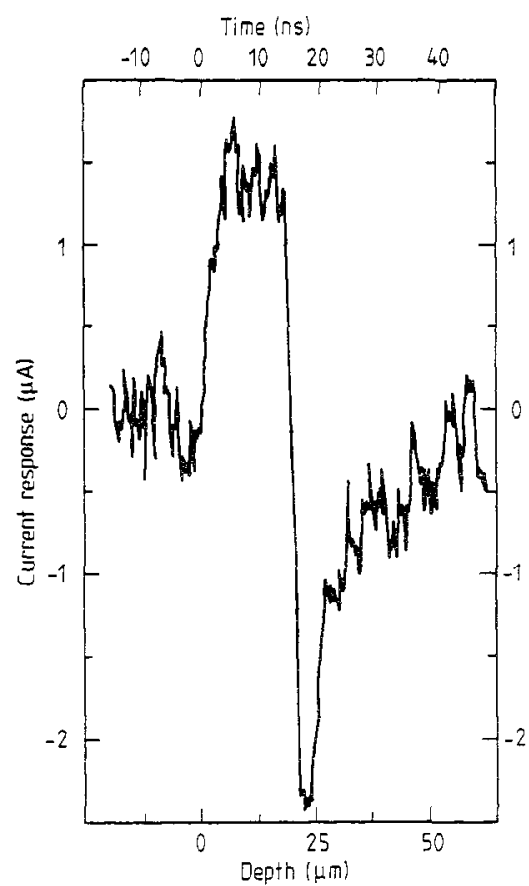

Figure 4. Current response of ( $\cong$ field distribution in) $25 \mu \mathrm{m}$ Tefion-FE? charged with $20 \mathrm{keV}$ electron beam. Step wave entering through surface opposite to charged surface. Calibration factor $C=I / E=3.8 \times 10^{-14} \mathrm{~A} \mathrm{~m} \mathrm{~V}^{-1}$.

The pressure-step response of another $25 \mu \mathrm{m}$ thick Teflon-FEP-electret is shown in figure 4 . The sample had been metallised on one side, charged through its unmetallised surface with an electron beam of $20 \mathrm{keV}$ energy to a total charge density of about $0.2 \mathrm{mC} \mathrm{m}^{-2}$, and stored for $53 \mathrm{~d}$ before removal of the metal electrode and measurement. In this case, the step wave entered through the sample surface opposite to the one facing the charging electron beam. The penetration depth of the charge layer amounts to approximately $5 \mu \mathrm{m}$ in agreement with split-Faraday-cup results (Gross et al 1977).

The pressure step for the measurement shown in figure 4 was generated by means of a voltage step of $500 \mathrm{~V}$. An electrode area of $19.6 \mathrm{~mm}^{2}$ was used on the $25 \mu \mathrm{m}$ thick Teflon-FEP sample ( $R C$ time constant $0.73 \mathrm{~ns}$ ). Thus, the calibration factor $C$ according to equation (3) amounts to approximately $3.8 \times 10^{-14} \mathrm{~A} \mathrm{~m} \mathrm{~V}^{-1}$ in the present case. With this value and a relative permittivity $\varepsilon=2.1$, the current step of $0.38 \mu \mathrm{A}$ at the charge 


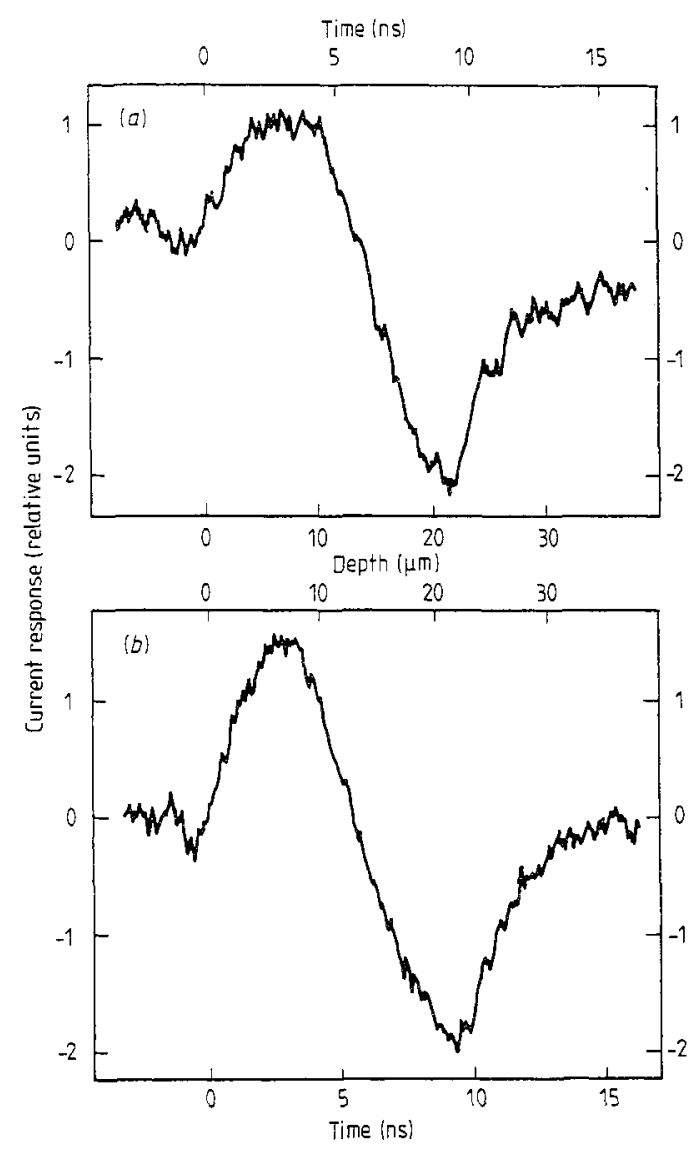

Figure 5. Current response of ( $\cong$ field distribution in) $23 \mu \mathrm{m}$ Mylar-PETP charged with $30 \mathrm{keV}$ electron beam. (a) Step wave entering through charged surface, (b) step wave entering through opposite surface.

laver position in figure 4 corresponds to an integrated charge density of about $0.19 \mathrm{mC} \mathrm{m}^{-2}$ which agrees very well with the initial charge density of $0.2 \mathrm{mC} \mathrm{m}^{-2}$ in the sample. The agreement indicates that the charge did not decay during the $53 \mathrm{~d}$ of storage of the Teflon-FEP foil.

In figures 5 and 6, the responses of a Mylar-PETP and a Hostaphan-RE-PETP sample, respectively, are depicted. The $23 \mu \mathrm{m}$ thick Mylar sample of figure 5 was metallised on both sides, electron-beam charged with an energy of $30 \mathrm{keV}$ and a current density of about $10 \mu \mathrm{A} \mathrm{m}^{-2}$ for approximately $35 \mathrm{~s}$, stored for $3 \mathrm{~d}$, and demetallised prior to the two measurements, one from each side (figure $5(a)$ and $5(b)$ ). The current response of this sample is shown in relative units. Transit times of about 10 ns agree well with the known sound velocity of $2.3 \mathrm{~km} \mathrm{~s}^{-1}$ in PETP (Sessler et al 1982a). The depth of the charge layer amounts to approximately $12 \mu \mathrm{m}$ in agreement with earlier charge-centroid measurements (Sessler et al 1982b). In this case, the $R C$ time constant of the sample was about 1.04 ns.

The $23 \mu \mathrm{m}$ Hostaphan-RE-PETP sample, the response of which is shown in figure 6 , had been metallised on one side, charged with a $20 \mathrm{keV}$ electron beam through the 


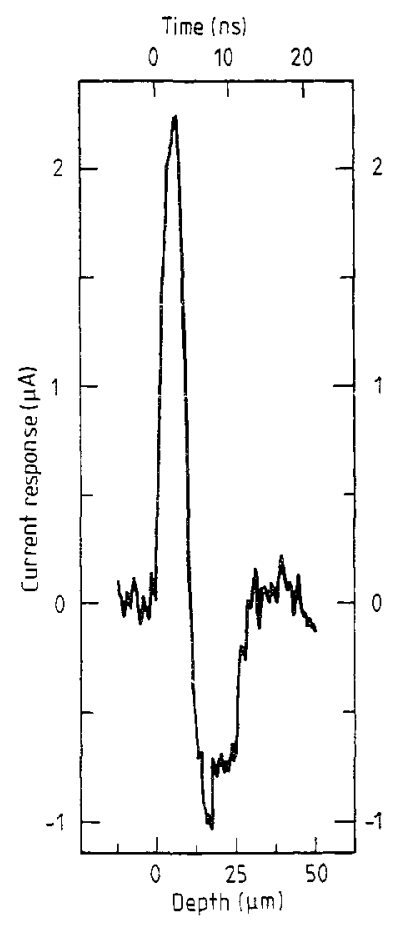

Figure 6. Current response of ( $\cong$ field distribution in) $23 \mu \mathrm{m}$ Hostaphan-RE-PETP charged with $20 \mathrm{keV}$ electron beam. Step wave entering through charged surface. Calibration factor $C=I / E=7.2 \times 10^{-14} \mathrm{~A} \mathrm{~m} \mathrm{~V}^{-1}$.

unmetallised surface to about $0.2 \mathrm{mC} \mathrm{m}^{-2}$, and demetallised before measurement. As seen from the figure, the transit time amounts to about $10 \mathrm{~ns}$, and the charge-layer depth of approximately $5 \mu \mathrm{m}$ is again confirmed by earlier split-Faraday-cup as well as electron-beam measurements (Sessler et al 1982b).

The step voltage of $600 \mathrm{~V}$ and the electrode area of $16 \mathrm{~mm}^{2}$ used on this $23 \mu \mathrm{m}$ thick PETP sample ( $R C$ time constant $1.0 \mathrm{~ns}$ ) result in a calibration factor of approximately $7.2 \times 10^{-14} \mathrm{~A} \mathrm{~m} \mathrm{~V}^{-1}$. Thus, the current step of $0.33 \mu \mathrm{A}$ at the position of the electronbeam-deposited charge in figure 6 corresponds (with $\varepsilon=3.25$ ) to an integrated charge density of $0.13 \mathrm{mC} \mathrm{m}^{-2}$. This value indicates that the initial charge density of $0.2 \mathrm{mC} \mathrm{m}^{-2}$ decayed by about one-third during the overnight storage of the PETP sample. A charge decay of this order is to be expected for PETP foils (Broemme et al 1981).

\section{Conclusions}

It has been shown that the PPS technique can be used with adequate accuracy for the determination of field distributions in charged dielectrics. Among other results, it is possible to obtain the location of charge layers as well as the magnitude of the charge or the field in the sample from these measurements. Use of larger pressure amplitudes and cooling of the samples will probably improve the signal-to-noise ratio and reduce attenuation and dispersion especially in Teflon-FEP samples.

The present accuracy of the PPS method amounts to about $\pm 1 \mu \mathrm{m}$ when charge-layer positions are evaluated. At the moment, calibration of the current response is possible with an accuracy of better than $\pm 10 \%$. Further calibration experiments are planned in order to improve the quantitative aspects of the pressure-step technique. 
Together with the LIPP technique, there exist now two complementary high-resolution pressure-wave methods for the detection of charge, polarisation, or field profiles in thin dielectrics. Both methods are based on the transit of an acoustic wave through the sample under investigation, thus translating a spatial distribution into a temporal signal.

\section{Acknowledgments}

The authors are grateful to D Broemme, $\mathrm{K}$ Holdik, Dr K Labonte, and I E West for stimulating discussions during the experiments and to $\mathrm{H}$ Eisenhauer for sample preparation. Thanks are also due to the Deutsche Forschungsgemeinschaft which provided financial support for both collaborating groups.

\section{References}

Alquié C, Charpak G and Lewiner J 1982 J. Phys. Lett. 43 L687-93

Alquié C, Dreyfus G and Lewiner J 1981 Phys. Rev. Lett. 47 1483-7

Broemme D, Gerhard R and Sessler G M 1981 Ann. Rep. Conf. Electr. Insul. Diel. Phenom. (Piscataway: IEEE Service Center) pp 129-35

Collins R E 1975 Appl. Phys. Lett. 26675-7

1976 J. Appl. Phys. 47 4804-8
1977 Rev. Sci. Instrum. 48 83-91

- 1980 J. Appl. Phys. 51 2973-86

1981 Ferroelectrics $3365-74$

Darmon D, Laurenceau P, Dreyfus G and Lewiner J 1979 J. Electrostatics $875-9$

De Reggi A S, Guttman C M, Mopsik F I, Davis G T and Broadhurst M G 1978 Phys. Rev. Lett. 40 $413-6$ Eisenmenger W 1982 Fortschritte der Akustik FASE/DAGA 82 (Bad Honnef: DPG) pp 33-46 (in German) Eisenmenger W and Haardt M 1982 Solid State Commun. 41 917-20

Eisenmenger W, Haardt M and Holdik K 1982 Ann. Rep. Conf. Electr. Insul. Diel. Phenom. (Piscataway: IEEE Service Center) pp 52-7

Faick M. Dreyfus G and Lewiner J 1982a Phys. Rev. B 25 5499-508

- 1982b Phys. Rev. B 25 5509-14

Gerhard-Multhaupt R 1983 Phys. Rev. B 27 2494-503

Gross B, Sessler G M and West J E 1977 1977 J. Appl. Phys. 48 4303-6

Haardi M 1982 PhD Thesis Stuttgart: Physikalisches Institut der Universität (in German)

Haardt M and Eisenmenger W 1982 Ann. Rep. Conf. Electr. Insul. Diel. Phenom. (Piscataway: IEEE Service Center) pp 46-51

Hauver G E 1965 J. Appl. Phys. 362113-8

Holdik 1983 to be published

Laurenceau P, Ball J, Dreyfus G and Lewiner J 1976 C. R. Acad. Sci. Paris Ser. B $283135-8$

Laurenceau P, Dreyfus G and Lewiner J 1977 Phys. Rev. Lett, 38 46-9

Migliori A 1979 Ann. Rep. Conf. Electr. Insul. Diel. Phenom. (Washington, DC: National Academy of Sciences) pp 315-24

Migliori A and Hofler T 1982 Rev. Sci. Instrum. 53 662-6

Migliori A and Thompson J D 1980 J. Appl. Phys. 51 479-85

Rozno A G and Gromov V V 1979 Pis'ma Zh. Tekh. Fiz. 5 648-51 (Sov. Tech. Phys. Lett. 5 266-7)

- 1980 Zh. Fiz. Khim. 54 2604-6 (Russ. J. Phys. Chem. 54 1482-4)

1981 Zh. Fiz. Khim. 55 1597-9 (Russ. J. Phys. Chem. 55 901-2)

von Seggern H 1978 Appl. Phys. Lett. 33 134-7

Sessler G M 1980 Electrets (Topics in Applied Physics vol 33) (Heidelberg: Springer-Verlag)

Sessler G.M. West J E, Berkley D A and Morgenstern G 1977 Phys. Rev. Lett. 38 368-71

Sessler GM, West J E and Gerhard R 1981 Polym. Bull. 6 109-11

- 1982a Phys. Rev. Lett. 48 563-6

Sessler GM, West J E and von Seggern H 1982b J. Appl. Phys. $\mathbf{5 3} 4320-7$ 
Sessler G M, West J E, Gerhard-Multhaupt R and von Seggern H 1982c IEEE Trans. Nucl. Sci. NS.29 $1644-9$

Sessler G M, Gerhard-Multhaupt R and West J E 1983 Proc. 11th Int. Congr. Acoustics: Rev. Acoust. Hors. Ser. 2 195-8

Tong D W 1980a Conf. Rec. 1980 IEEE Int. Symp. Electr. Insul. (Piscataway: IEEE Service Center) pp $179-83$

__ $1980 \mathrm{~b}$ Ann. Rep. Conf. Electr. Insul. Diel. Phenom. (Washington, DC: National Academy of Sciences) pp 359-65

—— 1982 IEEE Trans. Electr. Insul. EI-17 377-85

Wilhelm HE 1982 J. Phys. D: Appl. Phys. 15 2035-43 